\title{
DORA D'ISTRIA: RECEPTAREA SCRIERILOR PRINCIPESEI ROMÂNCE IN ITALIA
}

\author{
DORA D'ISTRIA: RECEPTION OF THE WRITINGS \\ OF A ROMANIAN PRINCESS IN ITALY
}

\author{
Aurora MARTIN 1 \\ https://doi.org/10.52744/9786062613242.14
}

\begin{abstract}
Rezumat: O figură renascentistă de anvergură, Dora d'Istria (pseudonimul literar al prințesei Elena Ghica Koltzoff-Massalsky -1828-1888) este una dintre cele mai rafinate intelectuale ale secolului al XIX-lea. Scriitoare, dedicată atât istoriei cât şi sociologiei, cercetătoare de talie europeană, Dora d'Istria a fost o figură proeminentă a Europei secolului al XIX-lea. In opera sa, de inspirație modernă, ea a abordat aspecte precum relația dintre valorile creştine şi progresul umanității, probleme legate de renaşterea națională a populațiilor est-europene sau probleme legate de îmbunătățirea condiției morale şi materiale a femeilor. A fost scriitoare, poliglotă (de la 10 ani vorbise deja 9 limbi străine), pictoriță, traducătoare, compozitoare şi interpretă de muzică, feministă - toate acestea l-au făcut pe biograful ei, Bartolomeo Cecchetti, să scrie că Dora d'Istria „a fost cu adevărat o enciclopedie vie”. Mai mult, ea a avut viziunea formării Uniunii Europene, pe care a văzut-o ca o viitoare uniune a statelor de tradiție neolatină. Dezvoltarea democrației, articulată pe doi piloni fundamentali, libertatea şi egalitatea, este unul dintre elementele fundamentale ale gândirii sale. Prin urmare, în spiritul unei reabilitări tardive a recunoaşterii contribuției celeilalte jumătăți la nivelul reprezentării în cultura europeană, îndrăznesc să spun că Dora d'Istria nu înseamnă mai puțin decât ceea ce a reprezentat prințul iluminat al Moldovei, Dimitrie Cantemir.
\end{abstract}

Cuvinte cheie: Dora d'Istria; Femei scriitoare; Italia

\begin{abstract}
A wide-ranging Renaissance-like figure, Dora d'Istria (the literary pseudonym of Princess Elena Ghica Koltzoff-Massalsky -1828-1888) was one of the most refined intellectuals of the nineteenth century. Dedicating herself both to history and sociology, researcher of European stature, d'Istria addressed issues such as the relationship between Christian values and the progress of humanity, the national rebirth of Eastern European populations or the improvement of the moral and material condition of women. She was also a polyglot (at age ten she had already spoken nine foreign languages), writer, painter, translator, composer, music performer, and feminist. The breadth of her achievements made her biographer, Bartolomeo Cecchetti, write that Dora d'Istria "was truly a living encyclopedia." Moreover, she had the vision of forming a European union, which she saw as a future union of states of neo-Latin tradition. The development of democracy, articulated on two founding pillars, freedom and equality, is one of the fundamental tenets of her thinking. Dora d'Istria surely takes an equal place beside the enlightened prince of the Moldavia, Dimitrie Cantemir.
\end{abstract}

${ }^{1}$ Conf. Univ. Dr. Universitatea Creştină Dimitrie Cantemir. Aurora.martin @ucdc.ro 
Keywords: Dora d'Istria; Women writers; Italy

Deşi a fost considerată, în Europa occidentală, una dintre cele mai respectate voci ale timpului său, din păcate, Dora d'Istria este prea puțin cunoscută în România, meritul unor scrieri definitorii în înțelegerea complexității personalității sale, a operei şi a contribuției substanțiale în mai multe domenii culturale şi sociologice revenind unor cercetători străini, cu precădere italieni.

În perioada 1876-1877, contemporanii i-au publicat parțial, unele lucrări, în vol. Operile principesei Dora d'Istria (1876), traduse de Grigore Peretz, cu o introducere a biografului ei Bartolomeo Cechetti, motivați, de bună seamă, de faptul că, atunci când s-a întors în țară, în 1875-1876, Regele Carol I i-a oferit Ordinul „Bene Merenti”, clasa I, pentru „merite literare remarcabile”, fiind pentru prima dată când o astfel de distincție era acordată unei femei.

Proiectată să apară în circa zece volume, din vasta sa operă au fost publicate doar trei. Chiar şi aşa, scriitori români, precum George Barițiu, Radu Ionescu, Gheorghe Ionescu-Gion, Cezar Bolliac au onorat prezența ei în cultura română, iar Nicolae Iorga, în introducerea la Lettres de Dora d'Istria (1932), scrie: ,...această femeie, de o rară orientare literară, cu o mare facilitate de scriitor, cu o curiozitate mereu trează şi cu un devotament neobosit pentru cauzele cele mai nobile, naționale şi sociale, care a fost Hélène Ghica”. ${ }^{2}$

Este drept că majoritatea scrierilor sale sunt în franceză, alegere care, cu siguranță a contribuit la receptarea lor în epocă şi la ecoul pe care l-au avut atât în mediile europene, cât şi în cele de peste Ocean. Racordată la marile probleme ale timpului său, a colaborat cu publicații prestigioase din diverse țări: Revue de deux Mondes, International Review, New York Tribune, Il Dritto, Observateur Belge, Gazette Rose, Courier şi multe altele. Scrierile sale în original sau în traduceri au apărut în Austria, Belgia, Elveția, Franța, Germania, Grecia, Italia şi Statele Unite ale Americii. Preferința pentru limba franceză, dar şi scrierile în italiană, germană, greacă, nu exprimă numai intenția de a se adresa unui public mai larg, elitist, ci demonstrează, în primul rând, conştiința apartenenței la intelectualitatea europeană a vremii. În acest sens, criticul literar şi publicistul Radu Ionescu scria: „Nu facem nici o imputare autorului [Dora d'Istria] că n-a scris în limba sa natală; a avut o fericită inspirație de a începe să scrie într-o limbă universală, care este pretutindeni înțeleasă." (Ionescu 1861, 430)

2 [În franceză, în original] A se vedea Iorga (1932, 134-209). 
$\mathrm{Cu}$ admirație față de abilitatea ei de a scrie în mai multe limbi străine, dar realizînd dificultatea cititorului român de a avea acces la operele ei, Iosif Vulcan, în revista Familia (Vulcan 1865, 213-215), spunea despre Dora d'Istria:

Ea a scris în limbele multe ca să-şi împlinească marea sa chemare mai cu succes, acuma însă, la dorința generală, şi-a dat promisiunea că va scrie şi în dulcea limbă maternă. Deie cerul ca cât de curând să vedem realizată această promisiune îmbucurătoare. Îmi place a crede ca brava română carea în opurile sale de atâte ori şi-a adus aminte cu frăgezime şi iubire de dulcea sa patrie nu va întârzia mult cu împlinirea dorinței celei mai intime a unei mame, carea cu nerăbdare aşteptă ca drăgălaşa sa fiică să vorbească în limba sa.

În timpul vieții, Dora d'Istria s-a bucurat de aprecieri elogioase din partea personalităților culturale europene şi nu numai, legând prietenii cu regele Frederic Wilhelm IV, Don Pedro II D’Alcantara, împătarul Braziliei, Edgar Quinet, cu patrioți albanezi cunoscuți, precum Dimitrie Camarada, Zef Serembe, Leonardo de Martino, dar şi cu numeroşi savanți italieni, printre care orientaliştii Gaspare Gorresio, Graziadio Isaia Ascoli, Michele Amari, Tullo Massarani. În corespondența cu Giuseppe Garibaldi, şi-a exprimat ideile politice, propunând planul organizării unei federații formate din state independente în Balcani, care să cuprindă italienii, albanezii, grecii şi românii. Într-una din scrisori spune: „Nu e departe ziua când, de la culmile Carpaților la țărmurile Mării Egee, steagul principelui român Mihai Viteazul ca şi cele ale lui Caragheorghe, Scanderbeg şi Canaris vor fâlfâi liber peste frumoasele ținuturi unde aceşti vajnici patrioți şi-au vărsat sângele”. Mai mult decât atât, ea îl încuraja pe Giuseppe Garibaldi, în 1861, să-şi impună influența asupra românilor, determinându-i să se răscoale împotriva Austriei. Garibaldi i-a răspuns doar că între poporul italian şi cel român există multe motive de afecțiune... La rândul său, Garibaldi i-a adresat o scrisoare, la 16 iulie 1861, cerându-i să exercite influența sa asupra românilor, pentru a-i determina să se răscoale într-o rebeliune împotriva Austriei.

Ideile sale de dreptate socială au apropiat-o şi de Jules Michelet şi Edgar Quinet, care țineau prelegeri despre egalitate, dreptate şi frățietate studenților şi intelectualilor parisieni. Biblioteca Academiei Franceze deține 14 scrisori ale Dorei d'Istria adresate lui Edgar Quinet. Nu este de mirare că mişcarea paşoptistă a fascinat-o3.

În articolul Dora d'Istria (Elena Ghica), Antonio D'Alessandri4 menționează:

3 Pictorul braşovean Mişu Popp a şi pictat-o în galeria sa de paşoptişti, portretul aflându-se la Muzeul de Artă Braşov. Un alt portret al său, realizat de Petre Mateescu, se află în Muzeul Național de Artă al României.

4 Antonio D’Alessandri este cercetător la Departamentul de Ştiințe Politice al 
La sfârşitul decadei 1850, Dora d'Istria şi-a lărgit sfera de preocupări, către politica internațională cu contribuții la ziarul Il Diritto din Torino. Aceste articole (1856-1857) se ocupă de Principatele Moldova şi Valahia care după Congresul de la Paris din 1856 au devenit o problemă centrală în politica internațională. Autoarea a pledat în fața comunității de cititori vesteuropeni pentru unirea şi autonomia acestor Principate, sub o dinastie domnitoare indigenă veche. 5

Publicarea unui număr însemnat de scrieri în Italia, la Trieste, Florența, Cosenza, Palermo şi Catania, a contribuit în mod substanțial la consolidarea statală a Regatului Italiei, la prima unificare, prefigurând Mişcarea Iredentistă italiană şi Mişcarea Memorandistă românească, în vederea completării unificării statelor pe care şi le asumase ca patrii de suflet $^{6}$. Italia s-a dovedit a fi, într-adevăr țara de adopție a scriitoarei, nu numai prin faptul că şi-a petrecut mai mult de jumătate din viaţă în diverse oraşe italiene, dar şi prin titlurile conferite de unele Academii şi Societăți: Membru corespondent al Ateneo Veneto di Scienze, Lettere ed Arti din Veneția, 8 martie 1868; Membru onorific al Academiei de Fizicămatematică şi statistică din Italia , 18 iunie 1868; Membru emerit al Accademia Raffaello - Urbino, 17 decembrie 1871; Membru al Societăţii pentru „L'incremento de Teatro in Italia” („Dezvoltarea teatrului în Italia”) din Florența, 21 ianuarie 1872; Membru al Accademia dei Quiriti din Roma, 1873; Membru onorific al Accademia Pittagorica din Napoli, 24 mai 1873; Membru al Società italiana per gli studi orientali, 9 noiembrie 1873 (transformată în 1877 în Accademia Orientale); Membru onorific al „Minerva” din Trieste; Membru al Accademia Nazionale dei Lincei.

În 1865, este invitată de municipalitatea oraşului Ravenna la serbarea dedicată împlinirii a 600 de ani de la naşterea lui Dante, alături de Giovenale Vegezzi Ruscalla, membru de onoare străin al Academiei Române. În anii 1867 şi 1868 a trăit în oraşul La Spezia, experiențele trăite aici fiind prezentate în lucrarea Il golfo di La Spezia, un studiu deopotrivă etnologic, geografic, geologic şi paleontologic, de o impresionantă erudiție.

De altfel, ultimii 20 de ani i-a petrecut mai mult în Italia, o perioadă stabilindu-se la Livorno, de unde corespondează cu unchiul ei Alexandru

Universităţii Roma Tre (Istoria Europei de Est şi Istoria contemporană). A studiat la Universitatea Roma Tre şi la École Normale Supérieure (Institut d'histoire moderne et contemporaine - IHMC) din Paris. Este secretar al Asociației Italiene de Studii din Europa de Sud-Est (AISSEE): http://host.uniroma3.it/associssioni/aissee/. Pentru teza sa de doctorat a primit premiul Spadolini - Nuova Antologia (2006) şi Premiul Soroptimist. Principalele sale interese de cercetare vizează istoria politică şi culturală a Europei de Sud-Est în epoca contemporană, cu o atenție deosebită la afirmarea şi dezvoltarea mişcărilor şi a statelor naționale.

5 A se vedea Leerssen (ed) (2018).

${ }^{6}$ http://www.orizonturiculturale.ro/ro_proza_Roberta-Fidanzia.html 
Dimitrie Ghica, fostul domnitor, retras la Napoli, după care se mută definitiv la Florența, unde îşi va afla sfârşitul, în urma unei banale hernii inghinale neglijate. Prin testament, averea a fost lăsată Primăriei din Bucureşti pentru administrarea spitalului Pantelimon, ctitoria familiei sale, iar tablourile, corespondența, cărțile rare, pinacotecii şi bibliotecii municipale din Florența. Villa D'Istria, în care şi-a petrecut ultimii ani, a fost lăsate primăriei din Florența, pentru ajutorarea unui sanatoriu de surdo-muți din Florența. După moarte, cenuşa i-a fost depusă la Cimitirul „Trespiana” din Florența.

In anul 1908 o piațetă din Florența a primit numele „Dora d'Istria” (între 6 iunie 1908 şi 24 septembrie 1912) (Bordaş 2008, 51-56), denumită astăzi „Piazza Isidoro del Lungo”.

Pe placa memorială instalată în anul 1915 acolo unde fusese „Villa d'Istria”, pe strada Leonardo da Vinci 28, i se face un portret succint şi cuprinzător: "De origine albaneză, româncă prin naştere, florentină prin adopțiune, s-a înnobilat şi s-a glorificat prin propriile ei merite, pentru virtuțile alese, de suflet şi talent, sub numele european Dora d'Istria ${ }^{\prime \prime}$.

Un citat din cartea scrisă de Roberta Fidanza este edificator, pentru nedreptatea istorică la care a condamnat-o posteritatea imediată:

Dora d'Istria, o reprezentantă de frunte a culturii europene din a doua jumătate a secolului al XIX-lea, s-a bucurat multă vreme - în timpul vieții ei - de o mare faimă în Europa şi Statele Unite ale Americii. Lucrările sale au fost publicate şi traduse în multe limbi, ceea ce i-a facilitat legăturile cu principalii exponenți ai culturii şi politicii din timpul ei, astfel încât şi-a meritat pe deplin numeroasele şi entuziastele aprecieri publice. După moarte, care a avut loc în 1888 la Florența, activitatea sa fost dată uitării şi chiar şi figura sa a fost ignorată şi lăsată deoparte. (Fidanzia 2013, 15) ${ }^{8}$

Posteritatea a ales să o ignore în istoria şi critica literară, însuşi George Călinescu făcându-i un medalion de scriitoare destul de sumar şi nedrept. În anii '8o, unele ziare româneşti se întrebau, totuşi, cum se face că o scriitoare atât de râvnită de marile academii ale lumii nu este membră a Academiei Române; răspunsul denotă misoginismul cu care elita intelectuală privea „femeile savante”. În acest context, este cu atât mai

7 La principessa Elena Koltzoff Massalski Ghika, 1828-1888, Albanese d'origine, Rumena di nascita, Fiorentina di elezione, nobilitò e glorificò se stessa. Per eccelse virtù d'animae d'ingegno nel nome europeo di Dora d'Istria.

8 „Dora d'Istria, elemento di spico della cultura europea della seconda metà dell'Ottocento, ha conosciuto per un lungo periodo - coincidente con la sua vita - grande notorietà in Europa e negli Stati Uniti d'America. Le sue opere sono state pubblicate e tradotte in molte lingue, consentendole di entrare in contatto con i principali esponenti della cultura e della politica del suo tempo, tanto da farle meritare numerose ed entusiasti elogi pubblici. Dopo la sua morte, avvenuta nel 1888 a Firenze, la sua attività ha conosciuto l'oblio ed anche la sua figura è stata dimenticata e lasciata in disparte." 
lăudabilă apariția, în decembrie 1988, în România literară, a unui articol intitulat $O$ publicistă de reputație europeană, semnat de Iordan Datcu.

În străinătate, însă, se dezvoltă astăzi o adevărată exegeză în jurul creației sale, care înregistrează chiar şi lucrări de doctorat, 9 datorate unor cercetători din Italia, Franța, ${ }^{10}$ SUA, Irlanda, Rusia. Mă voi opri cu precădere asupra studiilor dedicate de critica literară italiană operei sale şi rolului pe care l-a jucat în societatea vremii, pentru că, dintre țările Europei occidentale Italia este cea mai implicată în redescoperirea Dorei d'Istria, deşi are destule scrieri apărute şi în Elveția şi Franța Scrierile ei despre Liguria au fost reeditate critic de profesoara Luisa Rossi, care, pe lângă studii, a introdus-o în bibliografia cursului de istoria geografiei şi a explorărilor pe care îl ține la Universitatea din Parma. ${ }^{11}$

În volumul Dorei d'Istria Gli Albanesi in Rumenia. Storia dei principi Ghica..., traducătorul din franceză Bartolomeo Cecchetti a întocmit o bibliografie cuprinzătoare a scrierilor acesteia şi a făcut o clasificare a operelor scriitoarei, care s-ar împărți în nouă secțiuni: istoria literară (Studii asupra epopeilor poezia populară a Peninsulei Balcanice, Poezia populară a fino-mongolilor: Poésie des Ottomans, portrete literare - două portrete ale lui Eliade Rădulescu), probleme religioase, probleme sociale (problema feministă), economie politică şi agricultură, probleme artistice, politica, istoria, poeziile, viața orientală (serbările româneşti, schițe albaneze, scene din viața sârbească).

Dintre istoricii şi criticii literari italieni, care s-au ocupat de viaţa şi opera Dorei d'Istria, cele mai relevante lucrări sunt:

- Carlo Francesco Gabba ${ }^{12}$, La questione femminile e la Principessa Dora d'Istria, Considerazioni di Carlo Francesco Gabba, professore ordinario di diritto nella R. Università di Pisa. Firenze, Tipografia dei succesori Le Monnier, 1865;

- Bartolomeo Cecchetti, Di alcune opere della principessa Dora d'Istria. Cenni. Tipografia del commercio di Marco Visentini, Venezia, 1868;

- Angelo de Gubernatis, Dizionario Biografico degli Scrittori contemporanei. Ornato di oltre 300 ritratti ${ }^{13}$ Coi tipi Dei Successori Le Monier. Florența, 1879, 1317 pp. Articolul „D’Istria

\footnotetext{
9 Nationalism, Cosmopolitanism, and Female Intellectuality: The Paradoxes of Dora D'Istria and the Gendering of Risorgimento Italy, Altina Hoti, PhD., The University of Texas at Austin, 2019, Supervisor: Daniela Bini Carter.

10 Teza masterală a lui Laure Hinckel-Manea (2006).

${ }^{11}$ Tot ea a condus, la Universitatea din Florența, teza Elettrei Gullè asupra prințesei valahe.

12 Profesor de Drept civil la Universitatea din Pisa.

13 Dicționar Biografic al Scriitorilor contemporani. Împodobit cu peste 300 relatări scrise/portrete.
} 
(Dora)", pp. 386-387. De Gubernatis a scris un lung articol elogios cu titlul Illustri stranieri in Italia: Dora d'Istria [trad. Străini iluştri în Italia: Dora d'Istria], care a fost publicat în Rivista contemporanea, Torino, nr. 8o, 1869, vol. 57, pp. 107-115;

- A.Z. Pieromaldi, La principessa Elena Ghica, 1874;

- Oscar Greco, Bibliobiografia femminile italiana del XIX secolo, ${ }^{14}$ Venice, 1875, cap. II, Bibliografia della Principessa Dora d'Istria, 1855-1873, VII edizione, pp. 57-82, Presso i principali libri d'Italia - conține o bibliografie extinsă a scrierilor Dorei d'Istria;

- Operile dómnei Dora D’Istria. Traducțiune de Gregorie G. Peretz. Vol. I. Națiunalitatea română. Eroii României. Literatura română. Națiunalitatea helenică. Imprimate cu spesele Eforiei Spitalelor. Bucuresci. Typographia Curții (Lucrătorii Associați). 1876 (pe coperta originalului: MDCCCLXVI), 389 [-391] p. Cuprinde şi: Viața şi operile principesei Elena Ghica KoltzoffMassalski Dora D’Istria de Comendorele Bartolomeo Cecchetti cap de secțiune şi profesore la Archivele Regale din Veneția, membru al mai multor academii şi societăți savante. Autore al opului Republica Veneției şi curtea de la Roma şcl. (Traducțiune din limba italiană de Ştefan S. Sichleanu) ${ }^{15}$;

- Angelo de Gubernatis, Dizionario Biografico degli Scrittori contemporanei. Coi Tipi Dei Successori Le Monier. Firenze, 1879;

- Enrico Panzacchi, „Dora d'Istria,” în Nuova Antologia, vol. XVIII, Roma, 1888;

- Bartolomeo Cecchetti, „Necrologio. Dora d'Istria,” în Archivio Veneto, a. XVIII, t. XXXVI, fasc. 72, Venezia 1888, p. 484;

- Angelo De Gubernatis, La Roumanie et les roumains. Impressions de voyage et études. [Cu dedicație pentru V.A. Urechia, M. Constantin Esarcu, St. Sichleanu], Florence, Libraireéditeur Bernard Seeber, 1898;

- Paolo Mantegazza, Le donne del mio tempo. Una Principessa, Roma, 1905;

- Enciclopedia Italiana, volume 16, Roma, Istituto dell'Enciclopedia Italiana, 1932. Articolul GHICA [[3]], scris de Carlo Tagliavini: „Operele sale [ale Dorei d'Istria], publicate în special în Revue des deux mondes şi în Nuova Antologia, au contribuit în mod remarcabil la cunoaşterea în Europa a literaturii populare, a

\footnotetext{
14 Cartea se găseşte la Stanford University Libraries.

15 Titlul exact de pe coperta lucrării a fost reprodus după Bibliografia românească modernă 1831-1918, Vol. II (D-K), Editura Ştiinţifică şi Enciclopedică, Bucureşti, 1986, p. 144. Cartea se găseşte şi la Library of Congress, USA.
} 
îmbrăcămintei şi istoriei [popoarelor] Europei orientale." De asemenea, în acelaşi articol (Ghica) se menționează: „Familiei Ghica îi aparține scriitoarea Elena (1827-1888), cunoscută în Italia (unde a trăit mult timp şi unde a murit), cu pseudonimul Dora d'Istria";

- Petre Ciureanu ${ }^{16}$, „Dora d'Istria (II)”, articol în limba italiană, în Revue des Etudes roumaines, III-IV, Institut Universitaire Roumain Charles I, Fundația Regală Universitară Carol I, Paris, 1957, pp. 82-110; partea I a articolului a fost publicată în numărul revistei din 1954, pp. 169-192;

- Autunno a Rappalo: i bagni marini di una principessa in Liguria; a cura di Luisa Rossi, Genova, Sagep, 2000;

- Liviu Bordaş, Etnologie şi orientalism romantic în noile state Italia şi România: Angelo de Gubernatis, Dora d'Istria şi savanții români în a doua jumătate a secolului al XIX-lea. În: Acta Musei Porolissensis. XXVII. Istorie-Etnografie -Artă. Zalău, 2005, pp. 695-716;

- Antonio D’Alessandri, „Il „mito” di Dora d'Istria: un percorso bibliografico," în: Transylvanian Review, Vol. XV, No. 3 (Autumn 2006), pp. 45-70;

- Antonio D'Alessandri, Gândirea şi opera Dorei d'Istria. Între Orientul european şi Italia. Trad. din l. italiană de Mara Chirițescu şi Cerasela Barbone. Editura Pavesiana, Bucureşti, 2011;

- Antonio D'Alessandri, „Dora d'Istria fra Oriente europeo e Belpaese". În: Orizzonti culturali italo-romeni, Orizonturi culturale italo-române. Rivista interculturale bilingue, $\mathrm{nr} .7$, iulie, 2012, anul II;

- Liviu Bordaş (Universitatea din Bucureşti), Dora d'Istria e Angelo De Gubernatis: studiosi tra due Orienti. În: Seminario di studi - „Dora d'Istria intelletuale europea (1828-1888), Tra Risorgimento italiano e Risorgimento balcanico". Firenze, 30 mai 2008; idem în Ephemeris Dacoromana, Roma, 2012, pp.215-235;

- Roberta Fidanza, Dora d'Istria. Uno sguardo femminile sull'Ottocento. Risorgimento, pedagogia politica, condizione femminile, Colecția Donne nella storia, vol. 14. Aracne editrice, Roma octombrie 2013;

- Dora d'Istria. Storia di una principessa rumena a Firenze. 13 martie 2014;

16 Petre Ciureanu, profesor la Universitatea din Genova, i-a dedicat un amplu studiu critic - de fapt o micromonografie - în două numere succesive ale parizienei Revue des études roumaines. 
- Otilia Borcia, Dora D’Istria messagera della pace e dell'unione tra Oriente ed Occidente, Analele UniversitățiiCreștine Dimitrie Cantemir, Seria Ştiințele Limbii, Literaturii şi Didactica predării, nr 2/2014, pp 83-95;

- Roberta Fidanza, „Dora d'Istria: la storia politica di famiglia.” În: Filosofia e politica, n.1, 2016;

- Roberta Fidanza, Dora d'Istria. Le parole di una donna per la costruzione dell'Europa dei popoli, 2019.

Carlo Francesco Gabba, profesor la Universitatea din Pisa, în lucrarea sa La questione femminile e la Principessa Dora d'Istria (1865) analizează opiniile Dorei d'Istria în privința condiției femeii în timpul său; un citat asupra rolului scriitorului în societate, care reflectă gândirea scriitoarei este redat în continuare: „Madama Dora d'Istria è sopratutto una pensatrice. Per lei il bello sta nel vero, è la più nobile missione dello scrittore dei nostri giorni è quella di affrontare gli ardui problemi che faticano il secolo, e di additarne i bisogni." (Gabba 1865, 10) ${ }^{17}$

Angelo De Gubernatis, scriitor, lingvist şi orientalist, în scrierea sa La Roumanie et les roumains (De Gubernatis 1898, 180) afirmă: „Am avut onoarea de a publica în anul 1867, la Florența, în Rivista Orientale trei studii remarcabile de Dora d'Istria (prințesa Elena Ghica de România) asupra lui Heliade, G. Crețeanu şi asupra cronicarului Şincai”. În aceeaşi scriere (pp. 208-209), autorul apreciază că „Inainte de Carmen Sylva, Dora d'Istria era singura femeie-scriitoare din orientul balcanic, devenită ilustră în Europa... Ceea ce caracterizează mai ales opera literară a Dorei d'Istria este un melanj de spirit frondeur şi un înalt idealism umanitar.'

În 2007, Antonio D'Alessandri, profesor la Universitatea Roma Tre, publică monografia Il pensiero e l'opera di Dora D'Istria fra Oriente europeao e Italia, cea mai cuprinzătoare lucrare despre Dora D’Istria apărută până acum, şi tot el este cel care face traducerea acestei lucrări în limba română, în 2011 (Gândirea şi opera Dorei d'Istria între Orientul european şi Italia, Bucureşti, Pavesiana, 2011). Cartea include o genealogie a familiei Ghica şi este structurată pe şapte capitole, în care oferă informații generoase despre evenimentele din viața de copilă şi adolescentă a Elenei Ghica, despre călătoriile şi despre scrierile ei, cercetătorul propunându-şi, pe de o parte, să facă lumină asupra complexității gândirii Dorei D’Istria şi a evoluției sale în timp, pe de altă parte, să exploreze contextul în care s-a creat şi a circulat ceea ce el

${ }_{17}$ Doamna Dora din Istria este mai presus de toate o gânditoare. Pentru ea, frumusețea stă în adevăr, este cea mai nobilă misiune a scriitorului din zilele noastre de se confrunta cu problemele grele care contorsionează secolul şi de a le căuta o cale de rezolvare. (traducerea autoarei). 
numeşte „mitul” Dora D’Istria. Pentru a avea o imagine exhaustivă asupra ideilor sale politice şi religioase, Antonio D’Alessandri face o amplă şi riguroasă analiză bibliografică a scrierilor ei şi a recenziilor apărute, trecând în revistă articolele şi lucrările unor cercetători străini şi români asupra activității literare a autoarei. $\mathrm{O}$ atenție aparte acordă criticul corespondenței cu diverse personalități din epocă, din care se conturează portetul uneia dintre cele mai influente personalități feminine europene de la mijlocul secolului al XIX-lea, rolul pe care l-a jucat în panorama culturală europeană a vremii fiind acela de „trait d'union” între Orient şi Occident. „Urmând parcursul intelectual remarcabil al Dorei d'Istria, volumul pune în evidență totodată şi momentele fundamentale ale istoriei Italiei şi Europei secolului al XIX-lea, reconstruind o mare parte din relațiile cercetatoarei cu importanți exponenți ai culturii şi politicii, cum ar Giorgio Asproni, Angelo De Gubernatis, Giuseppe Garibaldi, Edgar Quinet, Lorenzo Valerio."

Cercetătoarea Roberta Fidanzia publică, la editura Drengo, din Roma, volumul intitulat Dora d'Istria. O privire feminină asupra secolului al XIX-lea, ${ }^{18}$ o traducere a propriei cărții apărute în original, în 2013, la editura romană Aracne sub titlul Dora d'Istria. Uno sguardo femminile sull'Ottocento.

Analize importante şi dezbateri i-au mai dedicat cercetători din diverse centre universitare din Italia, precum: Giuseppe Monsagrati, Maria Corrias Corona, Ginevra Conti Odorisio, Giuseppe Monsagrati, Rita Tolomeo şi Francesco Guida.

Personalitate de largă respirație europeană, Dora d'Istria face parte din galeria personajelor istorice doar aparent de ordin secundar, dar care prezintă o importanță fundamentală în demersul unei reconstrucții mai exacte a trecutului. În galeria prințeselor române care au impresionat Europa prin spiritul lor creator, prin cultura şi rafinamentul lor, a fost aşezată alături de contesa Ana de Noailles, de Martha Bibescu şi Elena Văcărescu.,Prin opera ei a ridicat atât de sus numele pe care i l-a dat tatăl ei şi a cinstit patria care i-a dat leagăn” (Paolo Mantagazza).

Nu este de mirare, aşadar, că, în epocă, unii autori au comparat-o cu trei personalități franceze binecunoscute, respectiv Madame de Staël, George Sand şi contesa Marie d'Agoult (cunoscută sub pseudonimul Daniel Stern).

În încheiere, o listă cu unele dintre cele mai importante scrierile sau traduceri ale scrierilor sale în italiană:

\footnotetext{
${ }^{18}$ Eveniment organizat la Institutului de Cultură şi Cercetare Umanistică „Nicolae Iorga” din Veneția, unde au participat autoarea, traducătoarea şi editorul Angelo Gambella, manifestarea fiind primită cu multă căldură de către un public de foarte bună calitate preponderent italian.
} 
- Les Roumains et la papauté. În: Spectateur de l'Orient, Atena, 1856-1857; trad. în italiană în Il Diritto, Torino, 1856; trad. în română de Gregorie P. Peretz, 2 vol. cu titlul Operile [sic!] dómnei Dora d'Istria, vol. I, p. 268, Bucureşti, Typographia Curtii, 18761877. Scrierea avea ca scop să justifice separarea românilor de papalitatea de la Roma;

- Osservazioni sull' organizzazione dei Principati Danubiani. În: Il Diritto, Torino, 2 aprilie 1856;

- La Svizzera italiana, schizzi. În: Il Diritto, Torino, 23 aprilie 1856;

- Un principe straniero nella Moldo-Valacchia. În: Il Diritto, 9 şi 17 septembrie, 3 şi 9 octombrie 1856 ;

- Roma. În: Il Diritto, 24 octombrie 1856;

- La propaganda austriaca nei Principati Danubiani. În: Il Diritto, 8 noiembrie 1856; trad. în română de Gregorie P. Peretz: Propaganda Austro-Romană in Principatele dunărene sèu despre rolul tradarei în istoria poporelor latine, în Operile dómnei Dora d'Istria, vol. I, pp. 261-267. [Autoarea susține ideea unității tuturor românilor situați pe teritoriul Daciei antice, atacă opoziția Austro-Ungariei contra Unirii Principatelor Române şi pune în lumină propaganda austriacă şi cea de la Roma, care urmărea, în acele timpuri, „să pună mâna pe provinciile dunărene" < citat textual >];

- Gli eroi della Rumania. În: Il Diritto, Torino, 1856-1857; trad. în română de Gregorie P. Peretz în Operile dómnei Dora d'Istria, vol. I, pp. 93-173, Bucureşti, 1876-1877. Personalitățile prezentate sunt: Radu Negru, Ion I-iu Bassarab, Dinastia Atzanilor «Asăneştilor», Mircea cel Betrăn, Ioan Huniad, Ştefan-cel-Mare. În ediția din 1887: Gli eroi della Rumenia. Profili storici, con prefazione di Paolo Mantegazza, Firenze, G. Barbéra, Editore, 1887, Piccola Biblioteca del Popolo italiano, semnatarul prefeței, Paolo Mantegazza, observă că rareori calități atât de puțin obişnuite se regăsesc împreună: „un corp de toată frumusețea, o inimă grațioasă şi nobilă, o rațiune de artist şi de gânditor";

- L'antico governo e la rivoluzione in Sicilia. În: Romita di Livorno, 8 septembrie 1860 ;

- La Veneziana, [roman istoric, scris între 1848 şi 1861]; publicat în: Illustrazione universale, Milano, 4 martie-6 mai 1867; trad. în

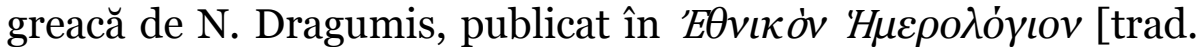
Almanah Național], Atena, 1865 (pseudonimul autoarei elenizat, într-un singur cuvânt: $\Delta \omega \rho \alpha \delta i \sigma \tau \rho ı \alpha) ;$

- Le Feste Rumene. În: Mondo illustrato, Torino, 25 mai şi 8 iunie 1861 (conține prima traducere în italiană, în proză, a baladei Miorița, precum şi a baladei Soarele şi luna; autoarea descrie 
dansurile, costumele naționale, obiceiurile de nuntă, de Crăciun şi de Paşte la români);

- La politica degli uomini e la politica delle donne, Constantinopol, 19 decembrie 1870 ;

- Les ètudes indiennes dans la Haute-Italie. Le Mahābhārata et le roi Nala ${ }^{19}$ [par] Dora d'Istria, Mémoire lu à la Société de archéologie de Athènes, II éd. Atena, Impr. J. Cassandréas, 1870. Publ. În Rivista europea, vol. III, fasc. 3, 1870. Trad. italiană: ed. a II-a, Firenze, (Tip. Dell'Associazione), 1870;

- Gli storici della letteratura tedesca, în: Evridiki, Constantinopol, 15 ianuarie 1872.

\section{Bibliografie:}

Bordaş, Liviu. (2008). „Operele incomplete ale Dorei d'Istria. Istoria unei ediții la 1870”, Caiete Critice, Bucureşti, 10-11: 51-56.

De Gubernatis, Angelo. (1898). La Roumanie et les roumains. Impressions de voyage et études. [Cu dedicație pentru V.A. Urechia, M. Constantin Esarcu, St. Sichleanu]. Florence: Libraire-éditeur Bernard Seeber.

Gabba, C.F. (1865). La questione femminile e la Principessa Dora d'Istria. Considerazioni di Carlo Francesco Gabba, professore ordinario di diritto nella R. Università di Pisa. Firenze: Tipografia dei succesori Le Monnier.

Fidanza, Roberta. (2013. "Dora d'Istria uno sguardo femminile sull'Ottocento. Risorgimento, pedagogia politica, condizione femminile," Donne nella Storia. 14. Roma: ARACNE.

Hinckel-Manea, Laure. (2006). Dora d'Istria et la question d'Orient dans la Revue des Deux Mondes, mémoire de maîtrise sous la direction de Catherine Durandin, Institut National des Langues et Civilisations Orientales - INALCO, Département Europe Centrale etOrientale, Langue Roumaine, spécialisation histoire, Paris, 2005-2006.

Ionescu, Radu. (1861). „D-na Dora d'Istria” (I-III), Revista română. Bucureşti. I: Helvetia germană. august 1861, pp.427-448. II-Viața monastică în Biserica Orientală, decembrie 1861, pp .783-806. III: Femeile în Oriente, aprilie 1862, pp.17-45.

Iorga, Nicolae. (1932). «Lettres de Dora d'Istria». Revue historique du sud-est européen, 9(4-6): 134-209. Paris-Bucureşti.

Leerssen, Joep. (2018). (ed.) Encyclopedia of Romantic Nationalism in Europe. University of Amsterdam. (electronic version: Amsterdam, Study Platform on Interlocking Nationalisms).

Operile dómnei Dora D’Istria. (1876). Traducțiune de Gregorie G. Peretz. Vol. I. "Natiunalitatea română. Eroi României. Literatura română. Natiunalitatea helenică". Imprimate cu spesele Eforiei Spitalelor. Bucuresci: Typographia Curții (Lucrătorii Associați).

Vulcan, Iosif. (1865). Familia, 18: 213-215.

19 Este o primă încercare de istorie a indologiei italiene. 